PR

46,7

1358

Received 30 June 2017

Accepted 9 August 2017

\section{Contextual ambidexterity and innovation in healthcare in India: the role of HRM}

\author{
Ashish Malik \\ Newcastle Business School, University of Newcastle, Ourimbah, Australia, and \\ Brendan Boyle and Rebecca Mitchell \\ University of Newcastle, Callaghan, Australia
}

\begin{abstract}
Purpose - The purpose of this paper is to examine innovation in the resource-constrained context of India's healthcare industry. It is argued that the process of innovation in addressing healthcare management challenges in such a context occurs through organisational ambidexterity and that human resource management (HRM) plays an important role.

Design/methodology/approach - A qualitative research methodology is applied to explore the role of HR practices in facilitating contextual ambidexterity and subsequent innovations in healthcare in India. The unit of analysis is the "case" of healthcare providers in India and in-depth interview and documentary data in two case sites are analysed to reveal the role of HRM in facilitating contextual ambidexterity and innovation. Data analysis was undertaken first at a within-case and then at a cross-case analysis level using interpretive manual coding based on how the data explained the role of HRM in delivering innovative outcomes and supporting organisational ambidexterity.

Findings - The authors found evidence of the use of sets of high-involvement HRM practices for exploration of new ideas and efficiency-driven HRM practices for creating contextual ambidexterity in the case organisations. Further, managerial/leadership style was found to play an important role in creating cultures of trust, openness, risk-taking and employee empowerment, supported by an appropriate mix of intrinsic and extrinsic rewards. Finally, training was also reported as being central to creating an ambidextrous context for delivering on various innovations in these healthcare providers.

Originality/value - This study represents an exploration of innovation in the context of India's healthcare sector through intersecting literatures of ambidexterity, innovation and HRM practices. In light of the emerging economy research context, an important empirical contribution is palpable. Moreover, through a study design which included collecting data from multiple informants on the role of human resources in facilitating innovative outcomes, the authors reveal the role of HR-related initiatives, beyond formal HR practices in creating contextual ambidexterity. This study also reveals the degree to which contextual idiosyncrasies enhance our understanding of the role of HR in facilitating innovation in emerging economies. Keywords Innovation, Qualitative, Healthcare, Ambidexterity
\end{abstract}

Paper type Research paper

\section{Introduction}

India is a populous nation that faces numerous social challenges, including that of providing access to quality and affordable healthcare (International Institute for Population Sciences and Macro International (IIPSMI), 2007). In addition to the scale of its healthcare challenges, unlike Anglo-Saxon nations that rely extensively on public healthcare infrastructure, the Indian context is unique in its extensive reliance on non-subsidised, privately funded healthcare. Reliance on private healthcare providers is as high as 70 per cent in urban areas and 60 per cent in rural areas (IIPSMI, 2007). The quality of care, though of a variable standard, comes at a cost that most Indians find difficult to afford. Until the mid-2000s, there was no

(c) Ashish Malik, Brendan Boyle and Rebecca Mitchell. Published by Emerald Publishing Limited. This article is published under the Creative Commons Attribution (CC BY 4.0) licence. Anyone may reproduce, distribute, translate and create derivative works of this article (for both commercial and non-commercial purposes), subject to full attribution to the original publication and authors. The full terms of this licence may be seen at http://creativecommons.org/licences/by/4.0/legalcode 
comprehensive national health insurance scheme for those living at the bottom of the economic pyramid (the "BoP"; earning less than USD5,000 per annum); this further compounded the challenge of accessing healthcare. Despite the recent development of a national scheme, access to quality healthcare is still a challenge for most. Furthermore, with the Indian healthcare industry now worth over USD110 billion in revenue and growing at a compounded annual rate of 16.5 per cent (IBEF, 2016), different classes of providers offering services to India's burgeoning middle class (referred to as the "middle of the pyramid" (MoP) are rapidly emerging. This has led to the rise of innovative tertiary and quaternary speciality hospitals to serve the MoP segment, which demands high-quality healthcare at reasonable costs. MoP providers have employed frugal, context-specific innovations in their business models and processes to help provide quality affordable care. They have implemented process and clinical innovations to simultaneously balance the exploration of new ideas with the exploitation of existing resources to provide a higher-end service within the resource constraints of a developing country (Prahalad and Lieberthal, 1998; Tiwari and Herstatt, 2012).

In a scholarly context, the simultaneous pursuit of exploration and exploitation of resources and knowledge has been defined as organisational ambidexterity, a characteristic central to innovation (O'Reilly and Tushman, 2008; Raisch and Birkinshaw, 2008). O'Reilly and Tushman (2008) define "ambidexterity" as organisation's ability to simultaneously develop learning processes by engaging in experimentation while also aligning with current goals, through refinement, efficiency and strong implementation routines. This ambidexterity leads to innovations that are both technological and administrative in nature (Raisch and Birkinshaw, 2008). Organisational ambidexterity is vital for achieving a variety of innovations; however, its role in facilitating administrative innovations (relating to processes, people and business models) are comparatively under researched (O'Reilly and Tushman, 2008; Raisch and Birkinshaw, 2008; Evan, 1966). Moreover, we would argue that the implementation of new technologies often brings about changes to a firm's service offerings or the way in which such services are delivered (Damanpour, 1987; Totterdell et al., 2002). Thus, innovation is defined in line with this study's goals and follows a broader management conceptualization, encompassing all new-to-firm changes in structures, processes and practices (Damanpour and Aravind, 2012) that are intended to achieve these healthcare organisation's goals. Innovation includes new activities by individuals, teams and users, which improves a health system's performance or caters to an unmet market need (Ansari et al., 2010). Such innovations in a healthcare context encapsulates developing new hospital processes, clinical procedures or a new business model for creating and capturing value for patients and the stakeholders through context-specific human resource (HR) and organisational management practices for delivering such innovations.

Additionally, the literature classifies innovations as administrative which occur when organisations change their processes and structure to implement new ideas, for example, by making changes to "the recruitment of personnel, the allocation of resources, the structuring of tasks, of authority, of rewards" (Evan, 1966, p. 51). Such innovations can be incremental (minor) and/or radical (significant) in nature. As explained by Tushman and O'Reilly (1996, p. 24), ambidexterity includes the "ability to simultaneously pursue both incremental and discontinuous innovation". In this context, exploitation often involves seeking improvements and refinements (incremental innovations) to the existing service portfolio, wherein the nature of change is generally minor and serves existing or similar markets, whereas exploration involves looking for variation in existing routines (discontinuous innovation) that is major or radical and leads to new products/services or the serving of new markets or customers.

Ambidextrous organisations are those that are successful in "simultaneously exploiting existing competencies and exploring new opportunities" without affecting their core business (Raisch et al., 2009, p. 685). There are inherent tensions in managing such a duality (March, 1991), and research into how firms manage these tensions is 
PR

46,7

1360

growing (Bledow et al., 2009; Cantarello et al., 2012; O'Reilly and Tushman, 2011), especially regarding organisations that face resource constraints - both internal and external. Such contexts amplify the need to balance exploration activities with the incremental exploitation of current activities (Cao et al., 2009). Thus, Indian's MoP healthcare providers serve as a "critical case" example of a context conducive to, and likely to benefit from, ambidexterity.

Finally, because ambidexterity is vital for achieving a variety of innovations, recent research has attempted to isolate specific mechanisms for achieving contextual ambidexterity, many of which point to the role of human resource management (HRM) practices and people management more broadly. For example, Caniëls and Veld (2016) found that high levels of simultaneous pursuit of exploratory and exploitative learning foster innovation. In another study, employees' functional tenure was found to be significant predictors of ambidexterity at the individual level (Mom et al., 2015). Similarly, Kapoutsis et al. (2016) highlighted a manager's political skills in balancing exploration and exploitation to be critical for achieving ambidexterity. People management and empowerment have been stressed through managerial capacity to take initiative (Frese et al., 1996), skills for negotiating and brokering change (Hargadon, 2002), tension resolution (O'Reilly and Tushman, 2011), willingness to empower others (Prieto and Pilar Pérez Santana, 2012), willingness to undertake risks (Chang and Hughes, 2012; Jansen et al., 2008, 2009) and facilitation of opportunities for employees to directly challenge the status quo (O'Reilly and Tushman, 2011). All of these mechanisms point to a role for HRM practices and people management in innovation.

Cognisant that management research consistently supports the role of innovation in organisational performance (Jiang, Wang, and Zhao, 2012; Jiang, Lepak, Hu and Baer, 2012; Prajogo and Ahmed, 2006; Smith et al., 2012), that ambidexterity is vital for achieving innovation through the simultaneous exploitation of existing resources in new ways and exploration of new opportunities (Raisch et al., 2009) and, finally, that mechanisms for achieving ambidexterity point to a critical role for HRM, we ask:

RQ1. What role do HR and management practices play in delivering innovative outcomes by simultaneously supporting the development of exploratory and/or exploitative learning (or ambidexterity) amongst Indian healthcare providers?

In answering the above research question, this paper seeks to add context-rich insights into the role of HR in ambidexterity and innovation, recognising two significant gaps in extant understandings. First, we note the equivocal existing evidence regarding the relationship between ambidexterity and performance across different contexts (Junni et al., 2013), which indicates the importance of context in examining this relationship. Some relevant research on healthcare firms catering to the BoP has been undertaken (Prahalad and Lieberthal, 1998; Tiwari and Herstatt, 2012). However, there is limited knowledge of how large superspeciality hospital chains catering to the innovative MoP segment simultaneously balance the exploration and exploitation of resources to deliver high quality but affordable healthcare. This gap remains despite the recent, dynamic growth of this segment in emerging economies, especially India. The paradox of managing high-growth rates in the presence of institutional voids presents a fertile opportunity for studying innovation and organisational ambidexterity amongst healthcare providers in a context more amiable to innovation than the highly regulated healthcare context of developed countries.

Second, we note that while research reveals that human and managerial factors can act as both catalysts and impediments to innovation (Prajogo and Ahmed, 2006; Smith et al., 2012); it is not clear how innovative firms foster the ambidexterity central to innovation or the role played by HR practices to this end. Moreover, reviews that have tried to identify the linkages between HRM and innovation (De Leede and Looise, 2005; 
Laursen and Foss, 2014; Seeck and Diehl, 2016) have shown that most studies have been undertaken in the USA, the UK and Europe, revealing a lacuna of research in developing country contexts.

The paper is organised as follows: we begin by providing a rationale for the research setting by reviewing the literature on innovation in healthcare in India. Next, we provide a review of the limited literature that connects HRM and ambidexterity to innovation. This is followed by a description of our methodology, findings, discussion and conclusion.

Innovation in healthcare services in emerging economies: India's challenges

With nearly four billion people (or nearly two-third of the world's population) living at the $\mathrm{BoP}$, innovation to support affordable access to quality healthcare services in developing and emerging economies is particularly important. India ranks 171st globally in terms of public spending on healthcare, and its doctor to patient ratio is 1:1,674, as compared to the World Health Organisation's average of 1:1,000 (IBEF, 2016). India has just 0.7 beds per 1,000 people, and 66 per cent of hospital beds are in urban areas whereas 69 per cent of the population resides in semi-urban and rural areas; therefore, the challenges to deliver affordable and quality healthcare are immense (Ramdorai and Herstatt, 2013).

However, research indicates that this challenging context can be conducive to innovation. The need to focus on developing context-specific innovations using technologies and process innovations appropriate to a given context has been widely acknowledged by scholars for some time (Schumacher, 1973), and evidence suggests that context-specific innovations are a feature of developing country markets and exist at the sharper and cost-effective end of disruptive innovations (Christensen and Rosenbloom, 1995; Prahalad and Hart, 2002). For example, through business model innovations, indigenous healthcare firms in India such as Aravind Eye Care Systems and Narayana Hrudayalaya offer highly efficient medical eye care costing from USD10 and open heart surgery for about USD2,000, respectively (Govindarajan and Trimble, 2012). Similarly, large MNCs such as GE Health Care, a research and development centre in India, has developed an inexpensive ECG (costing USD535) for the Indian market.

Although there is a growing body of research emanating from India's healthcare industry that focusses on, for example, "frugal" technological innovations (Tiwari and Herstatt, 2012), there is comparatively less research on administrative innovation or the role HRM plays in this context, despite the fact that so much of the productive output of hospitals is based almost entirely on the knowledge and care provisions of its HR.

Finally, we argue that the MoP segment of emerging economies is worthy of particular attention for a number of reasons. The MoP market segment consists of individuals earning between Indian Rupees (INR) 200,000 and 500,000 per annum, representing the second largest group and comprising 243 million people (USF, 2016). Firms severing this segment must simultaneously address the cost pressures of the BoP segment while meeting the lower end of the premium segment and accompanying demands for quality differentiation. Thus, they operate in a context necessitating both cost-effective innovation as well as innovation that adds value to consumers with higher expectations of quality. Competition, a known driver of innovation (Schumacher, 1973), is also intense, as most healthcare service providers operating in the Indian $\mathrm{MoP}$ segment are greenfield ventures initiated by large, highly competitive Indian business houses. The potential rewards for firms in the MoP segment are also noteworthy. The burgeoning middle class makes this a lucrative business venture; India's share of the global MoP segment is expected to rise from 11 per cent in 2020 to nearly 23 per cent in 2030 (Kharas, 2010, 2011). The value proposition of "affordable high-quality healthcare" in the MoP segment necessitates the delivery of a sustained level of innovative outcomes and "a powerful means for developing and broadening new markets" (Govindarajan and Kopalle, 2006, p. 190). This does not necessarily mean the delivery of 
PR

46,7

1362

healthcare innovations with high-end technologies but could include stripped-down and context-specific adaptations of existing technologies and/or innovative high-quality service provision. Competing in this segment requires healthcare firms to efficiently exploit existing resources whilst simultaneously exploring new learning for innovation. People are central to this process, and, therefore, developing an understanding of how HRM practices can create a context for innovation is highly relevant in India's competitive but resource-constrained healthcare system.

\section{HRM, ambidexterity and innovation outcomes}

Though previous research provides broad knowledge on how HR and organisational performance are operationalised in financial terms, the role of HRM in innovation and the mechanisms that affect ambidexterity are relatively underexplored (Shipton et al., 2006). More specifically, little is known about the role HRM plays in developing organisational ambidexterity (Prieto and Pilar Pérez Santana, 2012), which leads to innovation. While early management research on ambidexterity referred to the potential role of HRM practices, subsequent studies have failed to take advantage of this potential, and research is scarce on role of HRM in ambidextrous learning (Prieto and Pilar Pérez Santana, 2012).

Much of the literature exploring this topic focusses broadly on the impact of various bundles of HRM best practices or a configuration of HRM practices in performance (Boxall and Purcell, 2015; Delery and Doty, 1996). Following their review of the linkages between HRM and innovation, Seeck and Diehl (2016) argued that the assumptions underlying the relationship between HRM and performance are mirrored in the HRM-innovation link. Further, they noted that much of the research in this area has focussed on analysing the impact of universalistic best-practice bundles or a configurational approach to explaining innovation outcomes (Seeck and Diehl, 2016). Several HRM practices have been identified in the literature as having an impact on innovation (Beugelsdijk, 2008; Ceylan, 2013; Jain et al., 2012; Mumford, 2000; Schuler and Jackson, 1987) and ambidextrous learning (O'Reilly and Tushman, 2008; Lichtenthaler, 2009; March, 1991; Raisch and Birkinshaw, 2008). Consistent with the common argument in innovation literature that an organisation's ability to learn and integrate new ideas is central to innovation, studies focussing on HR have highlighted the role of specific HRM practices in achieving this goal such as training, performance management, reward systems and a learning culture (Foss and Laursen, 2003; Gupta and Singhal, 1993; Storey et al, 2002). These act as the key stimuli for developing a firm's learning and thus its innovative capacity. Scholarly literature in this area points to both the direct and indirect effects of HRM on innovation.

\section{HRM practices and innovation: direct effects}

Studies in various contexts examining the direct effects of $H R$ on innovation suggest a positive impact of HR practices. For example, using survey data from 1,900 Danish firms, Laursen and Foss (2003) found that from a bundle of nine HRM practices, seven were more conducive to innovation in manufacturing firms whereas two practices - internal and external training - were more important for innovation in service sector firms. Evidence from 173 Spanish firms supports a similar relationship (Jiménez-Jiménez and Sanz-Valle, 2008). Similarly, Lau and Ngo (2004) found a set of HRM practices to have a positive impact on product innovation in Hong Kong. Scholars focussing on the UK (Shipton et al., 2005) and Belgium (De Winne and Sels, 2010) noted that bundles of HRM practices act as the key determinants of innovation. Analysing the impact of HRM on technological and administrative innovations in China, Zhou et al. (2012) found a positive influence of both commitment-oriented and collaboration-oriented practices. In the HRM best-practice tradition, a study from India found a positive impact of training, employee involvement, performance management and employee welfare schemes on creating an innovation-oriented strategy (Cooke and Saini, 2010). However, while there are some similarities in the HRM requirements of firms operating in 
developing and developed countries, recent research also suggests marked differences, thus necessitating a context-specific understanding of the role HRM plays in supporting innovation (Srinivasan and Chandwani, 2014). Indeed, a variety of mediating and moderating factors might be considered based on insights from extant research.

\section{HRM practices and innovation: indirect effects}

Another stream of research in the literature explores the influence of various moderating and mediating factors. Key mediators include variables such as employee perception of highcommitment and high-involvement practices, creativity, work engagement and knowledge management (Seeck and Diehl, 2016). A behavioural perspective is often noted to reveal a mediating or moderating influence on the HRM bundle's overall impact on innovation (Mumford, 2000; Jiang et al., Wang, and Zhao, 2012; Jiang, Lepak, Hu and Baer, 2012; Schuler and Jackson, 1987). Amongst the earliest contributors to this field of research, Schuler and Jackson (1987) argued that empowerment-and trust-based job designs are conducive to the development of new ideas. Common moderators identified in the literature include the industry, culture, organisational structure and employees' task structures (Seeck and Diehl, 2016). Because industry is identified as a moderator of HR's impact on innovation, we postulate that in a knowledge-intensive service industry such as healthcare, people and HR practices may play a particularly strong role in facilitating innovation, despite a growing understanding that leveraging HRM advantages remains particularly challenging in this context (McBride and Mustchin, 2013). Perhaps as a consequence of this challenging context, there is a growing recognition of the need for effective people management practices in healthcare to improve organisational efficiency and patient outcomes, in part through innovative approaches to service delivery worldwide (Bartram et al., 2007). However, we argue that while the importance of effectively managing $\mathrm{HR}$ is now entrenched in healthcare policy discourse internationally (Australian Government Productivity Commission, 2005; Cabinet Office, 2006; World Health Organization, 2006), few comparisons can be drawn between the challenges in developed and developing country contexts. While the former have a long history of state investment and tight regulation at the high end, developing countries like India face unique HR, resourcing and demand challenges and consequently have an amplified need for ambidexterity. Therefore, we must carefully consider what is currently known about HRM's role in creating ambidexterity, i.e., an organisation's ability to simultaneously develop learning processes of exploration and exploitation (to refine and realign existing resources).

\section{HRM practices and ambidexterity}

A recent review exploring the relationship between ambidexterity and HRM suggests there are numerous HRM and organisational practices that act as antecedents for the creation of an ambidextrous context conducive to innovation (Junni et al., 2015). Junni et al.'s (2015) review points to multiple levels of influence, suggesting that employee-, leader- and HRM practice-level influences interact with organisational-level variables such as structure, culture and other contextual variables, which combined create an ambidextrous context. More recently, high-involvement and high-performance work systems have been noted to create a social climate that supports an ambidextrous context through a number of ability-, motivation- and opportunity-enhancing HRM practices (O'Reilly and Tushman, 2011; Patel et al., 2013; Prieto and Pilar Pérez Santana, 2012; Prieto-Pastor and Martin-Perez, 2015). For example, in a survey of 215 SMEs from the USA, Patel et al. (2013) found that disparate sets of HRM practices can deliver both alignment and adaptability for achieving ambidexterity. Prieto and Pilar Pérez Santana (2012) found in their study of 198 Spanish firms that high-involvement HR practices facilitate the creation of a social climate, which fosters ambidexterity. Prieto-Pastor and Martin-Perez's (2015) study of 182 Spanish 
PR

46,7

1364

firms found management support plays a moderating role in the relationship between high-involvement HRM practices and ambidextrous learning. Ahammad et al.'s (2015) study of Israeli banks found that motivation-enhancing HRM practices helped create an ambidextrous context, while Rao-Nicholson et al. (2016) found a positive influence of HRM on ambidexterity, moderated by distributed leadership.

While the above research linking ambidexterity with HRM and innovation in developed country contexts provides some universal insights into this relationship (Ahammad et al., 2015; Prieto and Pilar Pérez Santana, 2012; Rao-Nicholson et al., 2016), there are continued calls to explore how firms create an ambidextrous context through HRM (Junni et al., 2015), in part due to the disproportionate focus on quantitative measurements of direct effects related to innovation, a limited understanding of process-related factors (Seeck and Diehl, 2016) and an absence of research in developing country contexts. Recent research on the process-related factors that might better explain the role of HRM in facilitating effective and innovative resource utilisation has pointed to the importance of ambidexterity (Burgess et al., 2015). Thus, we argue that in the absence of a firm understanding of HR's role in creating contextual ambidexterity, our understanding of HR's impact on innovative outcomes is limited. In their discussion of contextual ambidexterity, Gibson and Birkinshaw (2004) explain that when employees can simultaneously exercise "alignment and adaptability", the former facilitates the exploitation of existing routines and knowledge to execute an organisation's goals, whereas adaptability allows employees to explore new knowledge conducive to renewing existing routines. Such an approach requires employees to simultaneously undertake both modes (exploitative and explorative) of learning in their daily routines, therefore incurring significantly less coordination costs. This approach to ambidexterity assumes that through individual decisions on how to allocate time and resources firms can manage the duality of the two learning modes (Tushman and O'Reilly, 1996). This clearly places HR and people at the core of organisational ambidexterity. It is ultimately the people in the organisation who possess knowledge and the means by which new and context-appropriate applications of learning and resources can be exploited; their brains are the "repositories of an accumulation of how things work" (Marsick and Watkins 1999, p. 208), and their actions are the exploitation of learning in practice. Thus, though few studies have explored the topic, especially in a healthcare context, the role of $\mathrm{HR}$ and their management in creating ambidexterity is incontrovertible. In healthcare, research has emphasised the potential of ambidexterity to facilitate both the exploitation of existing knowledge and the exploration of new approaches to meet the increasing demand and more complex care needs emerging internationally (Burgess et al., 2015). This ambidexterity has even greater potential in developing countries such as India, where existing demand already heavily outweighs resource availability (Ramdorai and Herstatt, 2013). However, research in this area is still in its infancy. We ask:

$R Q 1$. What role do HR and management practices play in delivering innovative outcomes by simultaneously supporting the development of exploratory and/or exploitative learning (or ambidexterity) amongst Indian healthcare providers?

\section{Research methodology}

Yin (2003) explains that research aimed at answering "what" and "how" questions should use qualitative methods in order to deal with processes that need to be linked. A priority for this study was to identify a methodology that acknowledges context specificity. To this effect, Yin (2003), who defines a case study as an empirical investigation into contemporary phenomenon operating in a "real-life context", highlights some relevant considerations. A qualitative case-based approach is particularly valuable where the kind of control present in a laboratory is not feasible or justifiable and when an understanding of context that incorporates the views of the "actors" is sought (Yin, 2003). 
In keeping with our discussion above, the unit of analysis is the "case" of MoP healthcares providers in India. Following Yin (2003), our study aims at theoretical and literal replications; therefore, data collection took place at two case sites. In-depth interview data with key informants from the two sites were collected in addition to documentary data from both organisations. The interview questions were developed based on the review of the literature summarised above. While data collection was informed by prior research (Dubois and Gadde, 2002), our analysis sought to critically appraise its applicability/boundaries in our specific research context. That is, while the extant degree of theoretical guidance available for the study was sufficient to focus the collection of data within a defined unit of analysis, guided by current theorizing, this research was exploratory in our developing country context.

\section{Data collection}

Semi-structured interviews were conducted in two highly innovative and high-growth MoP healthcare firms in India. The study employed purposive sampling to select highly innovative firms using insights from expert informants (Eisenhardt and Graebner, 2007). Through the researchers' professional networks established over nearly two decades of research in India, HR managers and consultants offering HR, management and other consulting services in the healthcare industry in India were asked to identify large super-speciality hospital chains that have implemented some form of innovation. A total of six hospital chains were identified by these experts, and invitations for access was sought. In-depth interviews, ranging from 60 to 120 minutes in length, were conducted at the two case organisations that agreed to participate and with nine key informants, including the most senior HR manager in each case site, the CEO, business development managers, nurses, clinicians and site heads. The interviews were transcribed verbatim, yielding a total of 172 pages of transcripts and 60,606 words of textual data. Additional secondary data from the public domain, organisational documents and policies were reviewed.

A maximum variation purposive sampling logic was followed to recruit interviewees to access multiple perspectives on the role of HRM and HR in ambidexterity and innovation in these case sites. The selection of organisations also included "peer nomination" by our expert informants as such an approach has been described as a "reliable and valid technique" (Howell and Higgins, 1990, p. 326). People tasked with overseeing an HR process, service or business model innovation were specifically selected for interviews. Multiple perspectives on the role of $\mathrm{HR}, \mathrm{HRM}$ and management practices in facilitating ambidexterity were sought beyond those provided by the most senior HR manager at the two case sites. Because HR activity is often devolved, site/unit head, nurses, physicians, surgeons, a training manger, CEO and even a project manager's perspective were included (because each had previously been tasked with overseeing the innovation taking place at the case sites). As a knowledge-and service-intensive industry, HRM is central to healthcare provision, and therefore, our analysis would have been limited if we had chosen to only interview the hospitals' HR managers.

Data analysis followed a cumulative process from basic pattern analysis to interpretive coding at a within- and cross-case level, which focussed on how the data addressed the research question. A constant interplay between theories that informed the empirical context led to the exploration of sub-categories and categories for developing first- and second-order concepts and themes, as well as a focus on the aggregate dimensions that the data set supported. This is a vital step in strengthening internal validation (Eisenhardt, 1989). The iterative process of coding the raw data, linking it back to the literature on high-involvement work systems, ambidexterity and innovation (Van Maanen et al., 2007) and looking for extensions in existing literature allowed us to balance the acknowledgement of existing theoretical insights while maintaining sufficient "theoretical detachment" (Andersen and Kragh, 2010) to explore the phenomena in its real-life, developing country context consistent with the study design. 
PR

46,7

1366
Figure 1.

Conceptual model mapping the relationship between high-involvement HRM work system, ambidexterity and innovation
Through this systematic "combining", we were able to transparently report the data while developing a new organising framework for identifying key HRM practices that support ambidexterity and innovation (Gioia et al., 2012).

To add further enhance clarity, the two-step manual coding process is presented in Figure 1. The first-order-subcategory concepts represent the pattern analysis of activities that underlie innovation in the case sites. The second-order categories are the aggregate coding that encapsulates the HRM practice represented by these activities. This step is intended to integrate appropriate insights for the extant literature. With this technique, the analytic process involved both reporting of raw data provided by interviewees, as their examples of innovative activities, and the application of concepts from the literature now shown to analytically relevant, e.g. such as what is known about empowerment and job design that can now help embed our finding with previous research. This technique provides transparency to the role of the researcher in the analysis of the data and provides clarity in relation to what is contextually different about this data and what can be appropriately integrated with the existing insights from the literature (Bryman and Burgess, 1994).

Themes emerging from the data are presented in bold and italics in our findings and discussion section that follows, while illustrative interview quotes are presented in italics.

\section{Findings and discussion}

In summary, both cases demonstrated the creation of an ambidextrous context by investing in appropriate employee behaviours and supportive high-involvement HRM practices. This helped achieve a number of innovation outcomes. Certain HRM practices were seen as critical enablers of what respondents called appropriate soft technology that allowed the formation of an ambidextrous culture. As one interviewee explained that this was about behavioural training through formal or informal peer interaction as well as formalised training. More specifically, HRM practices in each firm supported exploration and exploitation activities through connecting mechanisms what we coded as behavioural bridges (see Figure 1) for achieving ambidexterity and innovation. These bridging mechanisms included the presence of ambidextrous managerial/leadership behaviour to create room for experimentation while still placing appropriate boundaries on resource use. This is similar to O'Reilly and Tushman's (2011) toleration and resolution of the tensions in facilitating ambidexterity, the difference here being that this was deliberate and planned. Another major theme across both cases were the role of employee




empowerment and acceptable risk (similar to Prieto and Pilar Pérez Santana's, 2012 and Chang and Hughes' 2012 expectations). This gave employees leeway to experiment in process and business model innovations. Finally, another major theme across the data for both cases was the importance of allowing employee voice to challenge the status quo. This occurred through suggestion schemes and employee initiated quality improvement programs, as well as through offering differentiated rewards and benefits for those willing to innovate. Employees were found to be motivated to balance experimentation in parallel with the existing core business practices. The following section provides a detailed case-level analysis of how these themes were manifest in the data. We begin by providing an overview of these hospitals and then provide a thematic cross-case analysis of how HR and management practices created an ambidextrous context as depicted in Figure 1.

\section{Case 1 overview: a maternity care hospital chain in India}

Employing about 1,400 employees, this hospital chain specialises in providing innovative and specialised mother and child care in five of the largest cities in India. The hospital offers several new to market and new to country innovations in this market segment. These include in addition to specialised foetal medicinal and advanced intensive care, educational classes for the young parents, family support systems, hospitality and extended care at home for the new parents who are typically living away from their homes in larger cities. In recognition of its service and innovative approach to what is essentially a very established and basic surgical procedure, this hospital chain has received dozens of national awards.

\section{Case 2 overview: a super-speciality hospital chain in India}

As a super-speciality chain of nine hospitals operating, in the main, in Tier 2 metropolitan and tourist cities, this chain also acquired brownfield sites and gradually converted them into super-speciality hospitals. By focussing on three to four core specialities, this chain has achieved the efficient exploitation of core specialisations. This also helped establish routines for scaling this approach across the entire chain. This hospital employs local nursing and allied staff; however, to differentiate itself through innovative and affordable high-quality services, partnered with Harvard Medical School and recruited Indian specialists living overseas who were keen to return to the country.

\section{Creating an ambidextrous context}

Patient- and business-centric values

Interviewees explained that HRM practices focussed on creating a work culture that reinforces the values emphasising the personal credibility of nurses and clinical staff; developing a strong bias-for-action and employing what was termed behavioural coaching for both managers and employees as a way to reinforce these values. Interviewees stressed that personal credibility was developed through ethical practice explaining that right from the way we treat our employees, the way we value and treat our customers, everything is ethical. It was reported that the personal credibility of employees and ethical practices have served as the foundational stone for delivering innovative services in these healthcare organisations. It was stressed that this values approach also created a basis for action (i.e. to learn and innovate because they could be trusted) as exemplified in the following quotes:

I would say integrity the way we have defined it is doing the right thing whether someone is watching or not [...]. Credibility it comes from that, personal credibility right. And I will do the right thing to whoever, no matter what. The second is, so what do I do? Is bias for action, which is the
Contextual ambidexterity and innovation 
PR

46,7

second value, which is I will not wait for permission or to be told to do something. I just go ahead and do it because I feel it's the right thing.

When it comes to having a bias for action, interviewees explained that this requires that the core ethical values that are embedded in the organisation makes this possible:

And ethics are very important. There have been circumstances of people getting on the ethical side or on the personal side, the right kind of decisions have been taken, and those people have been asked to leave the organisation immediately, so that the right signals are sent to people.

Some interviewees explained that it is ethics that led to innovation, ethical treatment:

Yeah so we found that there are ten basic areas where we make things different or better for our customers, right? So, some of them, one is of course integrity, our ethical treatment.

It was very apparent that these values promoted by the owners helped create a culture where innovation could be pursued. This was also evident in the words of a consultant gynaecologist/obstetrician who confirmed management's perspective, when suggesting it was the cornerstone of working in the hospital and the patient experience:

I am delighted to be associated with X hospitals. Providing exceptional, personalized care, within a culture that fosters new ideas and continuous innovation, is the cornerstone of the experience we are looking forward to deliver to our patients and their families at X hospital

Additionally, by developing respect for all employees and adopting a customer-centric" value system, the organisation has achieved an empowerment-based culture. Much idea generation is bottom-up (through employees balancing their personal credibility and bias-for-action), as well as through suggestions from service end-users, i.e., expectant mothers and their families. This was evidence in nurses being able to take customer-centric actions, adding initiatives that they felt reflected this value. As interviewees noted:

So here you have you know a customer service excellence [...] We had an event where you know the first babies who were born, the first 100 babies, the premmies, they were all invited back and you know we had a little celebration. [Referring to those who took these actions the interviewee stressed] I mean they're people who have been able to master the process [of customer-centricity] [...] because they have a very clear customer mandate or a customer promise right, and all their systems and processes are aligned to business systems, strategies and leadership.

Others were very explicit that the values, empowerment and culture had but one objective:

Our purpose is customer-centricity. So the whole idea is to do, give the customer the best experience $[\ldots]$.

In this hospital it was reported that new ideas generated by nurses through their interactions with service users are subsequently evaluated and, where appropriate, integrated into daily routines through the organisational value of compassion. This value was explicitly connected to innovation with an interviewee stressing that:

Innovation in my context, it really comes from a very deeply held value and practice of compassion, okay [...] I would say closer to the customer, closer to the core is compassion [...].

Routine idea sharing between hospital sites, as well as between clinicians, has also enabled improvements in clinical practice. Through the adoption of a sharing and an empowermentfocussed approach, high-involvement HRM practices have supported the exploitation of existing resources and routines for realising efficiency gains and achieving standardisation (see Figure 1). At the organisational level, for example, the decision to convert existing brownfield sites into maternity hospitals allowed for a shorter time-tomarket, as well as standardised care and cure packages in the heart of the city. 


\section{Role of high-involvement and empowerment-focused HRM practices in innovation}

In terms of the specific HRM practices, hiring, employee involvement, benefits and differentiated rewards were stressed as both innovative in using $\mathrm{HR}$, but also essential to learning and to process and business model innovations (see innovation outcomes Figure 1). Learning and development also played a vital role in expanding the capability of individuals to engage in the design and delivery of process and clinical innovations creating what interviewees in Case site 1 described as clinical and business model innovations.

\section{Focussed hiring for innovation}

The data coded under this theme reflected differentiated hiring practices for different professional groups in the case sites. The recruitment strategy for nurses was reported as a HR innovation in itself, while the recruitment of outside top talent (to bring in new ideas was considered essential to innovation at the organisational level). The focus on hiring nursing staff from local and regional areas helped reduce costs and retain nurses over a longer term in a market where there is a shortage of nursing talent. It was explained that while:

"Some recruitments are done at the national levels [...] we prefer local recruitments because for one thing is local recruitments tend to stay longer". "And again, if we're recruiting from outside, and especially if you want an experienced nurse OT nurse I'll give you an example. MICU, nurse. Then we pay them additional based on the skills".

In contract, the hiring of specialists was focussed on recruiting top talent that could bring in ideas based on international experience. This recruitment was directly related to innovation by interviewees, for example:

In terms of clinical innovation most of our super specialists are people who have trained at very good centers, and like for example our joint replacement surgeon he did the training in the UK for five years, then the urologist also now has got training in the UK for about four years [...] Our neurosurgeon has done a fellowship in the US, so these people what they do is whatever is [...] going on abroad they try and do it here as long as the cost is within the reach of the patient[s].

The empowerment of this talent to innovate was related explicitly to the recruitment discussion (i.e. hire top talent and give them some freedom). However, the empowerment of other categories of health professions, such as the abovementioned nurses was also stressed. That is, this theme of empowerment-focused work design for process and clinical innovations was reported as important across all categories of staff not just the top talent. An important finding in a cultural context like India's, traditionally characterised by significant hierarchy.

\section{Empowerment-focused work design for process and clinical innovations}

The presence of an empowerment-based culture and respect for employees was evident in the commitment of nursing staff to deal with problems and make a difference:

So basically empowerment is very important, because if they have a buy-in with the organisation's philosophy, then it's easier for you to disseminate that information lower down. So then it's easier for you to understand what's happening lower down as well, so that the information comes back to you. It's like a bouncing ball. If you throw it down, if it doesn't come up, then you're not [empowering].

It was reported in the second case study that limited regulation and the late manifestation of diseases (mainly due to emerging economy contextual issues related to poverty and procrastination by patients, which is not uncommon in the Indian healthcare system), provided the opportunity for specialists to undertake experimentation, resulting in clinical innovations, which would not be possible in the highly regulated environment of the West. 
PR

46,7

1370

This freedom and empowerment facilitated through bridging mechanisms of leaders and managers was reported as playing a significant role in innovation. For example, using their specialist clinical and research knowledge and applying it in the Indian context, specialists with overseas experience had undertaken stem cell research that has delivered major breakthroughs in treating complex conditions. These clinicians exercised their discretion and choice within an established area of practice through a relatively controlled environment (but one that is comparatively much less regulated than developed country contexts). In such cases, specialists were allowed and supported to be innovative in their treatments, and clinical care. As can been seen in the following extract this represented $a$ lot of freedom but yet, did not in the interviewees opinion, represent a lassie-faire approach:

Fundamentally the way that we engage with our doctors is [...] So we don't set any clinical boundaries $[\ldots]$ They have a lot of freedom. What we do is that before we bring a doctor on there is a very thorough credentialing and privileging process, [...] we privilege him to do $\mathrm{x}, \mathrm{y}, \mathrm{z}$, which could be cardiac surgery, cardiology, invasive, non-invasive, whatever it may be. Now once we've privileged him, the field is his [...]. whether he wants to innovate [...] try a new procedure in cardiology, he may take outside help, he may want to go for a training somewhere [...]. we're very open, flexible to clinicians taking their own clinical decisions. [But] Empowerment to us doesn't mean having a casual lassie-faire approach, but it means helping people achieve their outcomes [...] So it needs to add to productivity. [...] I can say discretionary extra role behaviours [done] right.

Another theme related to the Role of high-involvement and empowermentfocussed HRM was data on rewards and benefits.

\section{Employee rewards and benefits for clinical and process innovations}

Through involvement practices, the hospital soon realised the key pain points of their nursing staff: accommodation and transportation costs in a large metropolitan city - a critical employee benefit gap. As most nursing staff are typically engaged in shift work, the organisation decided to offer employee benefits in the form of subsidised (often shared) residential accommodation with point-to-point transfers from the nurses' hostel to the hospital to provide a safe environment for nurses. Notably, in this developing country context, this communal living for nurses was viewed positively and had beneficial knock on effects. This approach helped in fostering a sense of teamwork among the nursing staff sharing accommodation and reduced employee attrition.

Physicians, consultants and nurses were offered differentiated compensation packages based on their performance on improvement projects (i.e. linked to process innovations). Interviewees explained that compensation was used as a means to encourage service innovation. One example provided was being able to get paid more (flexible rewards) by adding new service innovations:

We are definitely not the best pay masters. But we have schemes where employees can earn a lot [...] For example [...] homecare [...] Generally [young] couples don't know how to handle babies. So for the first one week we take, or first one month they can choose to have the same nurse who [...] helped them out in the hospital, comes back home and helps with the baby bath and so on. And these are things that we just do so that the employees are able to earn a lot more [...]. There are small little celebrations that are thrown in. So one of our units just found a suite room is what patients want [...] I mean they found out that these guys are looking for something more [...] for a genuine sense of celebration [...] . So, they [nurses] devised a candle light dinner for the new mum and dad [...]

At the HR management level facilitating the flow of ideas was also rewarded. Line managers and physicians with line management responsibility are expected to gain and evaluate ideas and present them to the management. This brought efficiency and created routines for all staff to engage and innovate from the ground up. Again, this is quite a significant finding in light of the research context, as the approach to HRM was overcoming an appreciation of hierarchy 
deeply embedded in Indian culture. Recognising the efforts through monetary and non-monetary means stressed with a view to sustaining efforts to add new and better services:

Yes. We have something called employee recognitions which every month there will be a various nomination from individual teams. Based on their performance they are, HODs will shortlist okay this is the person should be recommended from nursing side [...]. Plus the certificates are given. Then there's also, I mean instead you get rewarded with cash prize also [...]. So we give a cheque of, you know, 1,000 rupees every month based on that. [...] Appreciation should be in all forms, it has to be monetary also.

Intrinsic rewards were also noted as important. It was reported that the specialists in this hospital are allowed opportunities for further professional development and to share the successes (partial or full) of their innovative procedures at international conferences. Celebrating innovation is considered an important part of the organisation cultural and a catalyst for cultivating external partnerships. It was reported that such forums have further afforded specialists' opportunities for exploration and generation of alternate ideas.

\section{Ambidextrous managers/leaders for process and business model innovations}

An important example of this theme in the data was when the hospital leadership realised the there was a huge and untapped market of young parents living away from their families in Tier 2 cities who could benefit from some ancillary educational, care and social support programs. The hospital successfully launched multiple service innovations and offered patient-driven solutions in the form of differentiated care and cure packages. Central to delivering this innovation were managers who could create an environment where new approaches could be implemented cognisant of the different perspectives of different staff members. That is, this was enabled by the presence of ambidextrous managers who often play the role of good cop/bad cop between nurses, physicians and ancillary staff. It was found that when facing resistance from clinicians and allied staff, the senior leadership in this hospital was tasked to play a dual role of good cop/bad cop, wherein the line managers were expected to both accommodate the new ideas and deal with resistance. An interviewee explained this as a soft and hard approach that as a team we did of course. It couldn't have been done by me alone.

The ability to embed duality of routine and non-routine was greatly facilitated by the above ambidextrous leadership and managerial styles.

Yeah, it does, it does. It's an open forum. It's not a controlled forum. So everyone has the right to speak out and challenge what they want [...] at the associate level or at my level there are challenges which we pose to each other every time, but at the same time the MD also can be challenged on some assumptions that she has made. So that's how the inclusive behaviour and openness is there, and freedom to work is there. Otherwise you feel stifled, you can't perform, you can't think out of the box.

Finally it was also reported that the performance management metrics for supervisory staff were set to encourage the generation and flow of ideas by encouraging and developing frontline staff. That this is linked to performance management and that the flow of ideas need to be facilitated in a hierarchical culture in an emerging economy context, is significant:

If you actually speak to another nurse you'll find a world of a difference in the level of confidence, in the level of assertiveness with which they will fight for things and you know, things that they don't agree with from the patient's perspective and somebody else is kind of [...] So they have a lot of say. Because it is heard, it is valued and it is implemented where it makes sense. So, and I think that's the kind of interaction she even has with the clinician.

A final distinct theme in the data was Learning and development for process, clinical and business model innovation. In line with predications in the HR 
PR

46,7

literature the important of learning and development in employee and organisational innovation was repeatedly stressed by interviewees. However, it was discussed in a manner that explicitly linked development to the core values of the hospitals and the fore mentioned empowerment culture.

\section{Learning and development for process, clinical and business model innovation}

Learning and development was reported as central to firms' innovative capacity. In terms of exploration, collectively, the flow of ideas and knowledge generated by nursing care staff and patients had resulted in the birth of a new business model. In part, the value of compassion towards patients was central to the birth of the new business model, wherein, in addition to relying on revenue from pure clinical and nursing care, the hospital decided to expand its portfolio of services to offer ancillary services such as educational programs for pre- and post-natal care, social events and celebrations of the birthing experience for new mothers and young families. This business/service model innovation was made possible through the abovementioned empowerment-based culture and the value placed on trust between the doctors, nurses and patients:

So once I do bias for action, I'm already building trust in the system. Unless I trust another person I wouldn't be able to do it, so people who have a delegation problem, who have a letting go problem will find it extremely difficult.

Internal team-fit was considered vital for supporting process innovations. In this context, it was noted that, the implementation of national and international accreditation quality standards served the dual purpose of high-quality market signalling and creating confidence amongst nursing staff who were developing with the hospital. Distinctive differences were noted, including the nurses' leadership approach following their training programme in the USA; as part of the programme, nurses were expected to lead several process and administrative innovation projects. The self-efficacy (Yu, 2010) of nurses who attended international training to improve the care experience of their patients was enhanced, and they were able to identify, lead and implement various operational and strategic process innovations in nursing care (that is there was a very direct link between this development and innovation). Examples were provided that included innovations to improve aspects of infant mortality, infection control and bedsores. It was apparent that the hospital's partnership with Harvard Medical School to deliver nursing leadership training also allowed the nursing staff to share knowledge with other nurses and allied medical staff such as technicians, as well as consult with clinicians and physicians to engage in routine and non-routine problem solving and experimentation. Additionally, the hospital partnered with one international and two national hospital quality accreditation bodies. In terms of driving innovation an interviewee explained the Harvard relationship evolved from design to clinical practices learning on an ongoing basis:

[...] it's almost 12 years now that we've had a relationship with, Harvard partners, and you know it's evolved from really facility design to clinical you know practice and knowledge sharing. [...] what we do with them [clinicians] is we get them out here, we go there. There's actually hands on clinical sharing, expertise development and sharing.

Linked to this, it was explained that behavioural coaching through direct reports allowed for some leeway to nursing staff to spend an allocated budget on service innovations. For example, for festive activities. Such activities have created a sense of ownership and empowerment among the nursing and clinical staff, which has encouraged them to take calculated risks critical for exploratory learning. Through the HR practice of behavioural coaching by supervisors, employees felt more comfortable engaging and generating new 
ideas. Most importantly, voice mechanisms were designed to facilitate interactions and the flow of ideas. As explained by a management interviewee:

Nursing is present at very high levels of leadership interactions. So, we structure it that way very purposefully [...]. the visibility of nursing is not restricted to the nursing zone [...] So basically my style of leadership [...] was definitely empowerment, freedom. At the same time, ensuring that the policies, practices are followed, which are organisational policies.

\section{Implications and conclusion}

In line with might be expected based on the literature, both case sites were found to rely on a bundle of efficiency-oriented (exploitation) and empowerment-oriented (exploration) HRM practices to achieve ambidexterity. The robustness of extant observations on HR's role in innovation, evidenced by our ability to effectually explain our findings in a developing country, in line with these insights from research in developed-country contexts, is notable. Assumptions regarding HRs role in facilitating innovation cannot be fully understood absent a balancing of the research insights gained in developed country contexts with sufficient empirical explorations of the validity and scope of these insights in new contexts. Our approach to theory development (i.e. the model we build based on our exploratory study) allows IHRM researchers to evaluate the explanatory power of existing perspectives, and whether they differ greatly according to context. It has been suggested that international management (and IHRM) researchers in particular, need to ask when and where a theoretical lens sheds light on phenomenon before we assume it applies, in part, or in full (Doz, 2011). That, despite our developing country context, some of our findings can be reliably explained with insights from extant literature, in no way trivialises these findings. In fact, the most current debates in the IHRM field explicitly accentuates the importance of considering context before adopting a universalist vs a contextual paradigm for future research (Farndale et al., 2017).

However, we also note the significant contextual idiosyncrasies found, with important implications for understanding of HRMs role in facilitating ambidexterity in a developing country contexts. In our exploratory methodology, we took a "dialectical approach" to developing new insight (Poole and Van de Ven, 1989). Consequently, we can consider how our findings fit with, and contribute to extant insights, in addition to articulating how contextual idiosyncrasies can enhance our understanding of their applicability and/or boundaries.

The first contribution relates to the role of contextual conditions in creating opportunities for innovation by health care professionals. The Indian healthcare context presents numerous challenges, but at the same time, it also presents possibilities for innovation to address these problems. For example, diseases that manifest in India are often diagnosed at an advanced stage, which limits the utility of proven medical procedures, thus necessitating innovation. As one specialist noted, they were dealing with complex primaries, a new concept in medical parlance: a condition which has occurred due to procrastination by the patients. Solving these conditions requires viewing them as an opportunity for clinical innovation and provides healthcare teams some discretion in undertaking clinical innovations. Moreover, a variety of supporting HR practices were found to be central to facilitating this ambidextrous context, including practices for hiring local (and regional) talent, developing performance management metrics for supervisors to actually facilitate the generation of new ideas, mentoring of frontline staff, flexible benefits, training, behavioural coaching, etc. These HR practices could all be used to facilitate ambidexterity because of the opportunities created by contextual conditions. How such innovation-friendly conditions might be replicated safely in a highly regulated developed economy context is a tantalising question for future research.

Furthermore, our findings that the hierarchy that generally exist in the healthcare industry (and which would be expected to be amplified in a hierarchical culture like India) 
PR

46,7

1374

were not pronounced in the cases studied, suggesting a strong role for HR practices in countervailing hierarchy, a significant finding in India (and by extension for HR research and practice in other hierarchical cultures). In this sense, the context of this study has stretched the boundaries of what be expected. That HR can have an impact here has generalisable implications. As social identities based on culture, profession and hierarchy have been shown to be a factor in the effectiveness of interaction across healthcare teams in the west (Mitchell and Boyle, 2015), the significance of HR's role in countervailing hierarchy has implications well beyond India.

The role of international collaboration is also noteworthy in light of the developing country context. New knowledge creation through external accreditation bodies such as Harvard Medical allowed frontline employees to identify better nursing solutions and implement various process innovations to improve clinical outcomes and the patient experience. The role of HRM in facilitating international collaborations, training and recruitment is central to adding capacity for innovation in developing countries. When coupled with HR practices which stress empowerment and experimentation the full benefits of international collaboration can be realised. The HR practices connecting both modes of learning were simultaneously performed by ambidextrous leaders who empowered staff to explore and experiment, in part by seeking feedback from patients. Contextualising knowledge gained overseas through feedback from patients and having lots of freedom to experiment, allows providers in developing countries the opportunity to both exploit and potentially extend knowledge. Additionally, the practice of using external accreditation supported the standardisation of routines to exploit common and specialist knowledge.

The second contribution of this study relates to insights into the ownership of HR activities underlying innovation. Both the methodology used (interviewing a variety of stakeholders, not just HR professionals) and the subsequent data collected revealed the devolved nature of many of $\mathrm{HR}$ activities that drive innovation. This has important implications for HRM, as the field continues to engage in a normative discourse asserting that the path to an HR professional's status lies in the role of strategic business partner (Wright, 2008). In these case studies, the organisational legitimacy of $\mathrm{HR}$ (and the role of $\mathrm{HR}$ in innovation) was earned at the coalface. Diverse respondents in this study articulated the role of HR in supporting the development of exploratory and/or exploitative learning (ambidexterity); this validates our proposition that people management is central to these processes. This finding has implications for a more widespread debate in $\mathrm{HR}$ regarding the broader issue of dismantling functional demarcations in organisations (Wright, 2008), and perhaps demarcations in researchers' minds. Innovative HR work in these case sites is both open to, and driven by, occupational groups that are central to the organisations' success (e.g. nurses, doctors and their unit managers).

A third contribution pertains to the implications of our findings for future research. It was apparent in our data that the healthcare context, particularly in a developing country, impacts the role HR plays in innovation. In the healthcare context, the focus is on customer (patient)-driven HR innovations; therefore, HR activity at the coalface (not between departments) was most revealing of how HR contributes to critical organisational innovation. In India, an important emerging economy, the empowerment and flexibility afforded for "experimentation" was explicitly noted to be beyond what would be possible in a western healthcare setting. Thus, an implication for future research is the need to further question whether mass or organisationally specific research is most appropriate for examining the role of HRM in innovation. The real "owners" of HR's role in innovation were not the HR mangers, rather ownership was devolved. This reflects an "integrated HRM", where people management and related processes are not only the purview of HR professionals (Gratton et al., 1999).

Finally, we note that the empowered and flexible approaches of these case hospitals operating in the MoP segment have implications for existing healthcare providers in 
developed markets, where institutional regimes often act as barriers to the development of innovative solutions. There is a scope for knowledge transfer, as well as an opportunity to introduce a disruptor in developed markets, by partnering with some established emerging market's MoP players. The behaviours of organisations and individuals in healthcare sectors worldwide are known to be regulated to a level of complexity that is second to none (Field, 2006). While we acknowledge that there are good reasons for this level of regulation, we also note that it has potentially negative consequences for innovation. Based on our findings, while working within regulatory constraints, hospital managers should design HRM and management practices to create an ambidextrous context that facilitates the delivery of sustainable innovation.

The main limitations of this study relate to questions regarding the generalisability of the findings in India in light of our sample size. However, as our argument that MoP healthcare providers serve as somewhat of a "critical case" example of a context conducive to ambidexterity was validated during data collection, we are in a position to make logical theoretical generalisations through the in-depth insights gained. The theoretical generalisations and contributions articulated above can be validly made against extant knowledge in the field of HR and specifically, how HR practices facilitate ambidexterity. In a more practical sense we note that as international business scholars have argued the emerging economies do share some common characteristics and environments in which firms operate (Peng, 2003), insights gained in our study in India have implications for managers operating in other MoP markets.

There are lessons to be learned for both developed and developing country practitioners from this study, not least that HR practices can play a central role in innovation despite resource constraints. In the healthcare industry, where productive output is based almost entirely on the knowledge and performance of its HR, our unpacking of HRM's role in facilitating organisational processes that underlie innovation is an important contribution.

\section{References}

Ahammad, M.F., Lee, S.M., Malul, M. and Shoham, A. (2015), "Behavioural ambidexterity - the impact of financial incentives on employee motivation, productivity and performance of commercial bank", Human Resource Management, Vol. 54, pp. S45-S62.

Andersen, P.H. and Kragh, H. (2010), "Sense and sensibility: two approaches for using existing theory in theory-building qualitative research", Industrial Marketing Management, Vol. 39 No. 1, pp. 49-55.

Ansari, S.M., Fiss, P.C. and Zajac, E.J. (2010), "Made to fit: how practices vary as they diffuse", Academy of Management Review, Vol. 35 No. 1, pp. 67-92.

Australian Government Productivity Commission (2005), Australia's Health Workforce, Productivity Commission, Melbourne.

Bartram, T., Stanton, P., Leggat, S., Casimir, G. and Fraser, B. (2007), "Lost in translation: exploring the link between HRM and performance in healthcare", Human Resource Management Journal, Vol. 17 No. 1, pp. 21-41.

Beugelsdijk, S. (2008), "Strategic human resource practices and product innovation", Organisation Studies, Vol. 29 No. 6, pp. 821-847.

Bledow, R., Frase, M., Anderson, N., Erez, M. and Farr, J. (2009), “A dialectic perspective on innovation: conflicting demands, multiple pathways, and ambidexterity", Industrial and Organizational Psychology, Vol. 2 No. 3, pp. 305-337.

Boxall, P. and Purcell, J. (2015), Strategy and Human Resource Management, 4th ed., Palgrave MacMillan, New York, NY.

Bryman, B. and Burgess, R. (1994), Analyzing Qualitative Data, Routledge, London. 
PR

46,7

Burgess, N., Strauss, K., Currie, G. and Wood, G. (2015), "Organizational ambidexterity and the hybrid middle manager: the case of patient safety in UK hospitals", Human Resource Management, Vol. 54 No. S1, pp. s87-s109.

Cabinet Office (2006), “The UK government's approach to public service reform: a discussion paper", London.

Caniëls, M.C.J. and Veld, M. (2016), "Employee ambidexterity, high performance work systems and innovative work behaviour: how much balance do we need?", International Journal of Human Resource Management, doi: 10.1080/09585192.2016.1216881.

Cantarello, S., Martini, A. and Nosella, A. (2012), "A multi-level model for organizational ambidexterity in the search phase of the innovation process", Creativity and Innovation Management, Vol. 21 No. 1, pp. 28-48.

Cao, Q., Gedajlovic, E. and Zhang, H. (2009), "Unpacking organizational ambidexterity: dimensions, contingencies, and synergistic effects", Organization Science, Vol. 20 No. 4, pp. 781-796.

Ceylan, C. (2013), "Commitment-based HR practices, different types of innovation activities and firm innovation performance", The International Journal of Human Resource Management, Vol. 24 No. 1, pp. 208-226.

Chang, Y-Y. and Hughes, M. (2012), "Drivers of innovation ambidexterity in small- to medium-sized firms", European Management Journal, Vol. 30 No. 1, pp. 1-17.

Christensen, C.M. and Rosenbloom, R.S. (1995), "Explaining the attacker's advantage: technological paradigms, organizational dynamics, and the value network", Research Policy, Vol. 24 No. 2, pp. 233-257.

Cooke, F.L. and Saini, D.S. (2010), "(How) does the HR strategy support an innovation-oriented business strategy? An investigation of institutional context and organizational practices in Indian firms", Human Resource Management, Vol. 49 No. 3, pp. 377-400.

Damanpour, F. (1987), "The adoption of technological, administrative and ancillary innovations: Impact of organisational factors", Journal of Management, Vol. 13 No. 4, pp. 675-688.

Damanpour, F. and Aravind, D. (2012), "Managerial innovation: conceptions, processes, and antecedents", Management and Organization Review, Vol. 8 No. 2, pp. 423-454.

De Leede, J. and Looise, J.K. (2005), "Innovation and HRM: towards an integrated framework", Creativity and Innovation Management, Vol. 14 No. 2, pp. 108-117.

De Winne, S. and Sels, L. (2010), "Interrelationships between human capital, HRM and innovation in Belgian start-ups aiming at an innovation strategy", International Journal of Human Resource Management, Vol. 21 No. 11, pp. 1863-1883.

Delery, J.E. and Doty, D.H. (1996), "Modes of theorizing in strategic human resource management: tests of universalistic, contingency and configurational performance predictions", Academy of Management Journal, Vol. 39 No. 4, pp. 802-835.

Dubois, A. and Gadde, L.-E. (2002), "Systematic combining: an abductive approach to case research", Journal of Business Research, Vol. 55 No. 7, pp. 553-560.

Doz, Y. (2011), "Qualitative research for international business", Journal of International Business Studies, Vol. 42 No. 5, pp. 582-590.

Eisenhardt, K.M. (1989), "Building theories from case study research", Academy of Management Review, Vol. 14 No. 4, pp. 532-550.

Eisenhardt, K.M. and Graebner, M.E. (2007), "Theory building from cases: opportunities and challenges", Academy of Management Journal, Vol. 50 No. 1, pp. 25-32.

Evan, W. (1966), “Organizational lag”, Human Organizations, Vol. 25 No. 1, pp. 51-53, available at: https://doi.org/10.17730/humo.25.1.v7354t3822136580

Farndale, E., Raghuram, S., Gully, S., Liu, X., Phillips, J.M. and Vidović, M. (2017), “A vision of international HRM research", The International Journal of Human Resource Management, Vol. 28 No. 12, pp. 1625-1639. 
Field, R.I. (2006), Health Care Regulation in America: Complexity, Confrontation, and Compromise, Oxford University Press, New York, NY.

Frese, M., Kring, W., Soose, A. and Zempel, J. (1996), "Personal initiative at work: differences between East and West Germany", Academy of Management Journal, Vol. 39 No. 1, pp. 37-63.

Gibson, C.B. and Birkinshaw, J. (2004), "The antecedents, consequences, and mediating role of organizational ambidexterity", Academy of Management Journal, Vol. 47 No. 2, pp. 209-226.

Gioia, D., Corley, K. and Hamilton, A. (2012), "Seeking qualitative rigor in inductive research: notes on the Gioia methodology", Organizational Research Methods, Vol. 16 No. 1, pp. 15-31.

Govindarajan, V. and Kopalle, P.K. (2006), "The usefulness of measuring disruptiveness of innovations ex post in making ex ante predictions" Journal of Product Innovation Management, Vol. 23 No. 1, pp. 12-18.

Govindarajan, V. and Trimble, C. (2012), Reverse Innovation: Create Far from Home, Win Everywhere, Harvard Business Press, Cambridge, MA.

Gratton, L., Hope-Hailey, V., Stiles, P. and Truss, C. (1999), "Linking individual performance to business strategy: the people process model", Human Resource Management, Vol. 38 No. 1, pp. 17-31.

Gupta, A.K. and Singhal, A. (1993), "Managing human resources for innovation and creativity", Research Technology Management, Vol. 36 No. 3, pp. 41-48.

Hargadon, A. (2002), "Brokering knowledge: linking learning and innovation", Research in Organizational Behavior, Vol. 24 No. 1, pp. 41-85.

Howell, J.M. and Higgins, C.A. (1990), "Champions of technological innovation", Administrative Science Quarterly, Vol. 35 No. 2, pp. 317-341.

IBEF (2016), "Healthcare industry in India", available at: www.ibef.org/industry/healthcare-india.aspx (accessed 21 December 2016).

International Institute for Population Sciences and Macro International (IIPSMI) (2007), National Family Health Survey (NFHS-3), 2005-06: India, Vol. I, IIPS, Mumbai.

Jain, H., Mathew, M. and Bedi, A. (2012), "HRM innovations by Indian and foreign MNCs operating in India: a survey of HR professionals", The International Journal of Human Resource Management, Vol. 23 No. 5, pp. 1006-1018.

Jansen, J.J.P., George, G., Van den Bosch, F.A.J. and Volberda, H.W. (2008), "Senior team attributes and organizational ambidexterity: the moderating role of transformational leadership", Journal of Management Studies, Vol. 45 No. 5, pp. 982-1007.

Jansen, J.J.P., Tempelaar, M.P., Van Den Bosch, F.A.J. and Volberda, H.W. (2009), "Structural differentiation and ambidexterity: the mediating role of integration mechanisms", Organization Science, Vol. 20 No. 4, pp. 797-811.

Jiang, J., Wang, S. and Zhao, S. (2012), "Does HRM facilitate employee creativity and organizational innovation? A study of Chinese firms", The International Journal of Human Resource Management, Vol. 23 No. 19, pp. 4025-4047.

Jiang, K., Lepak, D.P., Hu, J. and Baer, J.C. (2012), "How does human resource management influence organizational outcomes? A meta-analytic investigation of mediating mechanisms", Academy of Management Journal, Vol. 55 No. 6, pp. 1264-1294.

Jiménez-Jiménez, A. and Sanz-Valle, R. (2008), "Could HRM support organizational innovation?", The International Journal of Human Resource Management, Vol. 19 No. 7, pp. 1208-1221.

Junni, P., Sarala, R.M., Taras, V. and Tarba, S.Y. (2013), "Organizational ambidexterity and performance: a meta-analysis", Academy of Management Perspectives, Vol. 27 No. 4, pp. 299-312.

Junni, P., Sarala, R., Tarba, S.Y., Liu, Y. and Cooper, C. (2015), "The role of human resources and organizational factors in ambidexterity", Human Resource Management, Vol. 54 No. S1, pp. 1-28.

Kapoutsis, I., Papalexandris, A. and Thanos, I.C. (2016), "Hard, soft or ambidextrous? Which influence style promotes managers' task performance and the role of political skill", International Journal of Human Resource Management, doi: 10.1080/09585192.2016.1233447. 
PR

46,7

1378

Kharas, H. (2010), “The emerging middle class in developing countries”, Working Paper No. 285, OECD, Development Center, Paris.

Kharas, H. (2011), "The emerging middle class in developing countries", presentation at Brookings Institute.

Lau, C.M. and Ngo, H.Y. (2004), “The HR system, organizational culture, and product innovation”, International Business Review, Vol. 13 No. 6, pp. 685-703.

Laursen, K. and Foss, N.J. (2003), "New human resource management practices, complementarities and the impact on innovative performance", Cambridge Journal of Economics, Vol. 27 No. 2, pp. 243-263.

Laursen, K. and Foss, N. (2003), "New human resource management practices, complementarities and the impact on innovation performance", Cambridge Journal of Economics, Vol. 27 No. 1, pp. 243-263.

Laursen, K. and Foss, N.J. (2014), "Human resource management practices and innovation", in Dodgson, M., Gann, D. and Phillips, N. (Eds), Handbook of Innovation Management, Oxford University Press, Oxford, pp. 505-530.

Lichtenthaler, U. (2009), "Absorptive capacity, environmental turbulence, and the complementarity of organizational learning processes", Academy of Management Journal, Vol. 52 No. 4, pp. 822-846.

March, J.G. (1991), "Exploration and exploitation in organizational learning", Organization Science, Vol. 2 No. 1, pp. 71-87.

Marsick, V.J. and Watkins, K.E. (1999), Facilitating Learning Organizations: Making Learning Count, Gower Publishing, Ltd., VT.

McBride, A. and Mustchin, S. (2013), "Crowded out? The capacity of HR to change healthcare work practices", The International Journal of Human Resource Management, Vol. 24 No. 16, pp. 3131-3145.

Mitchell, R. and Boyle, B. (2015), "Professional diversity, identity salience and team innovation: the moderating role of open-mindedness norms", Journal of Organizational Behavior, Vol. 36 No. 6, pp. 873-894.

Mom, T.J.M., Fourne, S.P.L. and Jansen, J.J.P. (2015), "Managers' work experience, ambidexterity and performance: the contingency role of the work context", Human Resource Management, No. S1, doi: 10.1002/hrm.21663.

Mumford, M.D. (2000), "Managing creative people: Strategies and tactics for innovation", Human Resource Management Review, Vol. 10 No. 3, pp. 313-351.

O'Reilly, C.A. III and Tushman, M. (2008), "Ambidexterity as a dynamic capability: resolving the innovator's dilemma”, Research in Organizational Behavior, Vol. 28, pp. 185-206.

O’Reilly, C.A. III and Tushman, M.L. (2011), "Organizational ambidexterity in action: how managers explore and exploit”, California Management Review, Vol. 53 No. 4, pp. 5-22.

Patel, P.C., Messersmith, J.G. and Lepak, D.P. (2013), "Walking the tight-rope: an assessment of the relationship between high performance work systems and organizational ambidexterity", Academy of Management Journal, Vol. 56 No. 5, pp. 1420-1442.

Peng, M.W. (2003), "Institutional transitions and strategic choices", Academy of management review, Vol. 28 No. 2, pp. 275-296.

Poole, M. and Van de Ven, H. (1989), "Using paradox to build management and organization theories", Academy of Management Review, Vol. 14 No. 4, pp. 562-578.

Prahalad, C.K. and Lieberthal, K. (1998), "The end of corporate imperialism”, Harvard Business Review, Vol. 76 No. 4, pp. 68-79.

Prahalad, C.K. and Hart, S. (2002), "The fortune at the bottom of the pyramid”, Strategy and Business, Vol. 26, pp. 54-67.

Prajogo, D. and Ahmed, P. (2006), "Relationships between innovation stimulus, innovation capacity, and innovation performance", R\&D Management, Vol. 36 No. 5, pp. 499-515. 
Prieto, I.M. and Pilar Pérez Santana, M. (2012), "Building ambidexterity: The role of human resource practices in the performance of firms from Spain”, Human Resource Management, Vol. 51 No. 2, pp. 189-211.

Prieto-Pastor, I. and Martin-Perez, V. (2015), "Does HRM generate ambidextrous employees for ambidextrous learning? The moderating role of management support", The International Journal of Human Resource Management, Vol. 26 No. 5, pp. 589-615.

Raisch, S. and Birkinshaw, J. (2008), "Organizational ambidexterity: Antecedents, outcomes, and moderators", Journal of Management, Vol. 34 No. 3, pp. 375-409.

Raisch, S., Birkinshaw, J., Probst, G. and Tushman, M.L. (2009), "Organizational ambidexterity: balancing exploitation and exploration for sustained performance”, Organization Science, Vol. 20 No. 4, pp. 685-695.

Ramdorai, A. and Herstatt, C. (2013), "Lessons from low-cost healthcare innovations for the base-of the pyramid markets: how incumbents can systematically create disruptive innovations", Working Paper No. 74, Technologie-und Innovationsmanagement, Technische Universität, Hamburg-Harburg.

Rao-Nicholson, R., Khan, Z., Akhtar, P. and Tarba, S.Y. (2016), "The contingent role of distributed leadership in the relationship between HR practices and organizational ambidexterity in the cross-border MandAs of emerging market multinationals", International Journal of Human Resource Management, doi: 10.1080/09585192.2016.1216882.

Schuler, R.S. and Jackson, S.E. (1987), "Linking competitive strategies with human resource management practices", Academy of Management Executive, Vol. 1 No. 3, pp. 207-219.

Schumacher, E. (1973), Small is Beautiful. A Study of Economics as if People Really Mattered, Blond Briggs, London.

Seeck, H. and Diehl, M.R. (2016), "A literature review on HRM and innovation - taking stock and future directions”, The International Journal of Human Resource Management, Vol. 28 No. 6, pp. 1-32, doi: 10.1080/09585192.2016.1143862.

Shipton, H., Fay, D., West, M., Patterson, M. and Birdi, K. (2005), "Managing people to promote innovation", Creativity and Innovation Management, Vol. 14 No. 2, pp. 118-128.

Shipton, H., West, M.A., Dawson, J., Birdi, K. and Patterson, M. (2006), "HRM as a predictor of innovation”, Human Resource Management Journal, Vol. 16 No. 1, pp. 3-27.

Smith, A., Courvisanos, J., Tuck, J. and McEachern, S. (2012), "Building the capacity to innovate: the role of human capital", research report, NCVER, Adelaide.

Srinivasan, V. and Chandwani, R. (2014), "HRM innovations in rapid growth contexts: the healthcare sector in India”, The International Journal of Human Resource Management, Vol. 25 No. 10, pp. 1505-1525.

Storey, J., Quintas, P., Taylor, P. and Fowle, W. (2002), "Flexible employment contracts and their implications for product and process innovation", International Journal of Human Resource Management, Vol. 13 No. 1, pp. 1-18.

Tiwari, R. and Herstatt, C. (2012), "Assessing India's lead market potential for cost-effective innovations", Journal of Indian Business Research, Vol. 4 No. 2, pp. 97-115.

Totterdell, P., Leach, D., Birdi, K., Clegg, C. and Wall, T. (2002), "An investigation of the contents and consequences of major organizational innovations", International Journal of Innovation Management, Vol. 6 No. 04, pp. 343-368.

Tushman, M.L. and O’Reilly, C.A. (1996), “Ambidextrous organizations: managing evolutionary and revolutionary change", California Management Review, Vol. 38 No. 4, pp. 8-30.

USF (2016), "Defining 'base of the economic pyramid' in India", available at: https://usf.vc/resources/ defining-base-of-the-economic-pyramid-in-india/ (accessed 24 December 24, 2016).

Van Maanen, J., Sørensen, J.B. and Mitchell, T.R. (2007), "The interplay between theory and method", Academy of Management Review, Vol. 32 No. 4, pp. 1145-1154. 
PR

46,7

1380

World Health Organization (2006), "Working together for health: the world health report 2006", Geneva.

Wright, C. (2008), "Reinventing human resource management: business partners, internal consultants and the limits to professionalization”, Human Relations, Vol. 61 No. 8, pp. 1063-1086.

Yin, R. (2003), Case Study Research: Design and Methods, 3rd ed., Sage, Thousand Oaks, CA.

Yu, Y-T. (2010), “Ambidexterity: the simultaneous pursuit of service and sales goals in retail banking”, doctoral dissertation, School of Marketing, Australian School of Business, The University of New South Wales, Sydney.

Zhou, Y., Liu, X.Y. and Hong, Y. (2012), "When Western HRM constructs meet Chinese contexts: validating the pluralistic structures of human resource management systems in China", The International Journal of Human Resource Management, Vol. 23 No. 19, pp. 3983-4008.

\section{Further reading}

Chang, Y.C., Yang, P.Y. and Chen, M.H. (2009), "The determinants of academic research commercial performance: towards an organizational ambidexterity perspective", Research Policy, Vol. 38 No. 6, pp. 936-946.

Lin, H-E. and McDonough, E.F. III (2011), "Investigating the role of leadership and organizational culture in fostering innovation ambidexterity", IEEE Transactions on Engineering Management, Vol. 58 No. 3, pp. 497-509.

Mark, S.K.M. and Akhtar, S. (2003), "Human resource management practices, strategic orientations, and company performance: a correlation study of publicly listed companies", Journal of American Academy of Business, Vol. 2 No. 2, pp. 510-515.

Perry, C., Riege, A. and Brown, L. (1999), "Realism's role among scientific paradigms in marketing research”, Irish Marketing Review, Vol. 12 No. 2, pp. 16-23.

\section{Corresponding author}

Ashish Malik can be contacted at: ashish.malik@newcastle.edu.au

For instructions on how to order reprints of this article, please visit our website: 